\title{
El establecimiento
}

y la modificación de

tributos como eventos

susceptibles de alterar

el equilibrio económico

del contrato estatal

\section{Felipe Rusinque ${ }^{1}$}

\section{RESUMEN}

La jurisprudencia del Consejo de Estado ha admitido, en abstracto, que la creación de un tributo o su modificación durante la ejecución de un contrato estatal son eventos capaces de alterar la ecuación financiera de este. Aquella Corporación ha entendido que el restablecimiento del equilibrio económico quebrado por la imposición o reforma de gravámenes fiscales puede fundarse en la teoría del hecho del príncipe o en la teoría de la imprevisión. Con todo, a pesar de dicho reconocimiento, cuando se analizan las circunstancias propias de cada caso en concreto difícilmente se están cumpliendo los requisitos necesarios para restituir el balance de la ecuación financiera.

1 Consultor independiente en Derecho Público, Bogotá, Colombia. Abogado de la Universidad Externado, Bogotá, Colombia y candidato a especialista en Derecho Contractual de la Universidad del Rosario. Email: feliperusinque@hotmail.com._Fecha de recepción: 15 de junio de 2017. Fecha de modificación: 30 de agosto de 2017. Fecha de aceptación: 30 de octubre de 2017. Para citar el artículo: RusINQUE, FeLIPE. "El establecimiento y la modificación de tributos como eventos susceptibles de alterar el equilibrio económico del contrato estatal", Revista digital de Derecho Administrativo, Bogotá: Universidad Externado de Colombia, n. ${ }^{\circ} 19,2018$, pp. 259-290. DOI: https://doi.org/10.18601/21452946.n19.11. 
Palabras clave: Equilibrio económico, Ecuación financiera, Establecimiento o modificación de tributos, Contrato estatal, Hecho del príncipe, Teoría de la imprevisión.

\title{
The establishment and modification of taxes as events susceptible to alter the economic equilibrium of public procurements
}

\begin{abstract}
State Council case law has recognized in abstract that new taxes or their modification, while a public procurement is in execution, are events susceptible to alter its economic equilibrium. In these cases, the restoration of the economic balance can be upheld by means of the theory of the fact of the prince and the hardship doctrine. Despite this possibility, after examining the particular circumstances of each case, the State Council has judged that the conditions to order the restoration of the economic equilibrium were not satisfied by the plaintiffs.
\end{abstract}

Keywords: Economic Equilibrium, Public Procurement, Taxes Modification, Fact of the Prince, Hardship Doctrine.

\section{INTRODUCCIÓN}

¿El establecimiento de un nuevo tributo o la modificación de los elementos de uno vigente, durante la ejecución de un contrato estatal ${ }^{2}$, son sucesos capaces de alterar el equilibrio económico de este? y, de ser así, ¿cuál sería el título jurídico con el que se restablecería dicho equilibro? Estas son las cuestiones jurídicas fundamentales que se abordarán en el presente escrito.

El establecimiento de un tributo es el acto general y abstracto por el cual este se crea y, más precisamente, tiene lugar con la expedición de una norma jurídica. Por otro lado, un tributo ya existente o vigente puede ser modificado, es decir, sufrir una reforma en alguno o varios de sus elementos: sujetos activo y pasivo, hecho generador, base gravable y tarifa ${ }^{3}$, procedimiento que también se realiza

2 "La etapa contractual o de ejecución del contrato administrativo se identifica por el período de tiempo durante el cual los contratantes deben ejecutar las prestaciones estipuladas, y comprende desde el perfeccionamiento hasta su finalización, independientemente del motivo determinante de esta. Es precisamente en esta etapa en la cual se ubica el tema del equilibrio económico en los contratos administrativos". LiBARDo RoDrícueZ, El equilibrio económico en los contratos administrativos, 2. ${ }^{\text {a }}$ ed., Bogotá: Temis, 2012, p. 7.

3 "En la obligación tributaria, aparecen por un lado el sujeto activo, que es la entidad estatal con derecho para exigir el pago del tributo, el sujeto pasivo o persona en quien recae la 
mediante la emisión de una disposición legal. Tanto el establecimiento como la modificación de un tributo implican la asunción o el aumento de cargas económicas para el sujeto pasivo del gravamen fiscal: el nacimiento de una obligación de dar una suma de dinero o el incremento en su monto, si ya existe. Ahora bien, las cargas económicas que comportan el establecimiento o la modificación de un tributo pueden causar el rompimiento de la ecuación financiera de un contrato estatal, siempre que la imposición de la obligación fiscal o su reforma sucedan con posterioridad al perfeccionamiento del contrato, graven a una de las partes del contrato y causen que la ejecución de las prestaciones a cargo de la parte gravada sea excesivamente onerosa ${ }^{4}$. La doctrina ${ }^{5}$ y jurisprudencia ${ }^{6}$ concuerdan en que el restablecimiento de la ecuación financiera del contrato estatal debe tener una causal o fundamento jurídico, dentro de los cuales están la teoría de la imprevisión y los títulos de imputación por los que la administración contratante tiene la obligación de restaurar el equilibrio económico: sujeciones materiales imprevistas, potestas variandi y hecho del príncipe. Razón por la que deben acreditarse, a su vez, los requisitos de procedencia propios de la respectiva causal o fundamento jurídico.

Para indagar si la ecuación financiera de un contrato estatal puede alterarse por una imposición tributaria creada o reformada luego del perfeccionamiento del contrato, es necesario considerar los reparos que descartan tal posibilidad. Bajo esta consideración, se procederá en primer lugar a analizar los argumentos que se oponen al restablecimiento del equilibrio económico desbalanceado a causa del nacimiento o aumento de una obligación fiscal, en cabeza de una de las partes del contrato. En seguida, se centrará la atención en los argumentos que están a favor del restablecimiento del equilibrio económico en la hipótesis bajo estudio. Habida cuenta de que el Consejo de Estado también se ha

obligación correlativa, el hecho gravado o situación de hecho indicadora de una capacidad contributiva a la cual la ley confiere la virtualidad de generar la obligación tributaria, y la base gravable y la tarifa, que son los elementos determinantes de la cuantía misma de la obligación". Corte Constitucional, Sentencia C-583 de 1996.

4 Libardo Rodríguez denomina a estos requisitos "Condiciones generales para la procedencia de la aplicación del principio del equilibrio económico" Cfr. Libardo RodríGueZ, El equilibrio económico en los contratos administrativos, cit., pp. 26 y ss.

5 "debe hacerse notar que el equilibrio económico del contrato puede alterarse por diversas razones o causales [...] Al respecto, debe señalarse que la importancia de realizar un análisis detallado y específico de las mismas radica, no sólo en su concepto, origen, evolución y justificación, sino, especialmente, en las particularidades que cada una presenta en relación con las condiciones que debe comportar la alteración de las circunstancias existentes al momento de contratar, y en la diversidad de efectos jurídicos que su aplicación genera". Ibíd., p. 32.

6 "Al respecto cabe señalar que la Sala ha [...] explicado también que el equilibrio económico del contrato puede verse alterado durante su ejecución, por las siguientes causas: 1. Por actos o hechos de la Administración contratante, 2. Por actos de la Administración como Estado; y, 3. Por factores exógenos a las partes del negocio jurídico". Consejo de Estado, Sección Tercera, Sentencia del 2 de septiembre de 2004, exp. 14.578. 
ocupado de la cuestión, se considerarán algunas decisiones en que el Máximo Tribunal Contencioso Administrativo resolvió situaciones problemáticas de desequilibrio contractual a causa de imposiciones tributarias. Por su número e importancia, son particularmente ilustrativas las providencias de aquella Corporación en las que se examinó si los contratos de obra pública en ejecución para el tiempo en que se estableció el "impuesto de guerra" podían desbalancearse, a causa de los mayores costos en que los contratistas incurrieron, pagando dicho gravamen.

\section{ARGUMENTOS EN CONTRA Y A FAVOR DEL RESTABLECIMIENTO DEL EQUILIBRIO ECONÓMICO}

De parte de quienes consideran que la creación de un tributo o su modificación no son eventos capaces de alterar la ecuación financiera de un contrato estatal se exponen tres argumentos. En primer lugar, se estima que de llegarse a reconocer que el equilibrio económico se quiebra a consecuencia del establecimiento de un tributo o de la reforma de alguno o varios de sus elementos, el Estado sería quien resultara gravado. Cuando se encuentra que la ecuación financiera del contrato estatal perdió su balance a causa la ocurrencia de un suceso imprevisto o imprevisible o por otra circunstancia atribuible a la administración, debe restablecerse el equilibrio ${ }^{7}$, lo que acarrearía que, tratándose de la alteración económica producida por la imposición o modificación de tributos, el valor de la obligación fiscal no lo asumiera el contratista, sujeto pasivo, sino la entidad contratante y, finalmente, sería el Estado quien se gravara a sí mismo ${ }^{8}$. El segundo argumento señala que como a todo contrato le son aplicables las leyes vigentes al momento de su celebración (art. 38 de la Ley 153 de 1887), la expedición de nuevas normas, incluso aquellas que crean o modifican tributos, no tienen efectos respecto de los negocios jurídicos ya perfeccionados. En tercer lugar, se aduce la circunstancia de que como el establecimiento de un tributo o su modificación deben hacerse mediante actos generales y abstractos ${ }^{9}$, no hay una ruptura del sometimiento ordinario de los

7 "Ese rompimiento del equilibrio financiero del contrato estatal, conlleva el deber de reparar o atenuar los daños producidos por actos o hechos extraordinarios e imprevisibles que se presenten con posterioridad a su nacimiento". Consejo de Estado, Sección Tercera, Sentencia del 31 de agosto de 2011, exp. 18.080.

8 "De manera que si el valor del contrato se incrementa en la suma que corresponde al porcentaje del impuesto, ello implicaría imposibilidad de hacer efectivo el gravamen y su traslado a la entidad pública contratante, con desconocimiento de la Constitución y de la ley". Consejo de Estado, Sala de Consulta y Servicio Civil, Concepto n. ${ }^{\circ} 637$ del 19 de septiembre de 1994.

9 "por tratarse de una competencia normativa se identifica con el poder legislativo, y se caracteriza por ser una actuación genérica, abstracta, indisponible, irrenunciable e imprescriptible, que no se extingue con su ejercicio, y recae en el Congreso de la República, las asambleas departamentales y los concejos municipales o distritales, en su jurisdicción". 
administrados a las cargas públicas, pues todos quedan gravados en iguales términos ${ }^{10}$.

Habida cuenta de que los títulos de imputación que fundamentan la obligación de la administración contratante a restablecer el equilibrio económico del contrato estatal -sujeciones materiales imprevistas, potestas variandi y hecho del príncipehan sido tratados por la jurisprudencia del Consejo de Estado como supuestos de responsabilidad contractual sin culpa ${ }^{1112}$, la importancia de este argumento estriba en desacreditar que haya habido un daño indemnizable, pues su causación está amparada por el acto jurídico que crea o modifica el tributo.

De otro lado, a favor de quienes sí encuentran en la creación o modificación de tributos supuestos de rompimiento del equilibrio económico del contrato estatal, se encuentran dos argumentos: el equilibrio económico está previsto por el Estatuto General de Contratación de la Administración Pública como un principio $^{13}$ (art. 27 de la Ley 80 ), una regla hermenéutica de los contratos estatales (art. 28 de la Ley 80), un derecho del contratista (art. 5.1 de la Ley 80), un derecho de la administración contratante (art. 4.3 de la Ley 80 ) y un deber de esta última (art. 4.9 de la Ley 80 ). En estos términos, el restablecimiento de la ecuación financiera debe realizarse siempre que se haya alterado durante la ejecución del contrato estatal, incluso si dicha alteración es producida por la imposición de un tributo o su modificación, pues así lo ordenan las disposiciones

RoberTo INSIGNARES y MARY SÁNCHEZ, "El poder tributario: Organización y estructura en el Estado colombiano", en Julio Piza (ed.), Curso de derecho tributario, procedimiento y régimen sancionatorio. Bogotá: Universidad Externado, 2010, p. 68.

10 Este fue uno de los argumentos expuestos por la Sala de Consulta y Servicio Civil del Consejo de Estado ante la consulta de si el "impuesto de guerra" podía alterar el equilibrio de los contratos de obra pública que gravó, raciocinio que a continuación se reproduce: "Este impuesto grava, a partir de la vigencia de la ley, la actividad particular dedicada a celebrar contratos principales o adicionales de obras públicas para la construcción y mantenimiento de vías, colocando a los sujetos pasivos en igualdad de condiciones frente a la ley y a las cargas públicas". Consejo de Estado, Sala de Consulta y Servicio Civil, Concepto n. ${ }^{\circ} 637$ del 19 de septiembre de 1994.

11 "la jurisprudencia ratifica la responsabilidad sin culpa de la administración, sobre la base de las teorías clásicas del derecho administrativo: hecho del príncipe, sujeciones imprevistas, imprevisión y enriquecimiento sin causa". LuIS BENAVIDES, El contrato estatal: Entre el derecho público y el derecho privado, 2. ${ }^{a}$ ed., Bogotá: Universidad Externado, 2004, p. 132.

12 "Igualmente, se recuerda que la responsabilidad contractual de una entidad pública contratante puede comprometerse con fundamento en la culpa, es decir, una responsabilidad con falta y por lo mismo subjetiva, derivada de una conducta de incumplimiento de las obligaciones contractuales; o con base en un fundamento objetivo como el derecho del contratista al equilibrio financiero del contrato y el deber de las entidades públicas de mantenerlo y restablecerlo, es decir, una responsabilidad sin falta (objetiva)". Consejo de Estado, Sección Tercera, Sentencia del 28 de junio de 2012, exp. 21.990.

13 "Este principio, consagrado en el artículo 27 del estatuto, consiste en que en los contratos estatales se mantendrá la igualdad o equivalencia entre los derechos y obligaciones surgidos al momento de proponer o de contratar". LiBaRDo RodríGuEZ, Derecho administrativo:

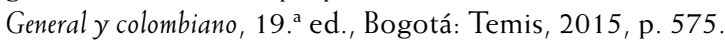


referenciadas y no se observa que haya una prohibición o exclusión expresa que deje a estas hipótesis por fuera de la regla general: la restauración del equilibrio económico. El otro argumento se halla en la jurisprudencia del Consejo de Estado. Se trata de algunos fragmentos de la parte motiva de las sentencias de esta Corporación sin fuerza vinculante, obiter dicta ${ }^{14}$, en los que se estudia en abstracto la posibilidad de que la imposición de un tributo altere el equilibrio económico de un contrato estatal y el título jurídico con que debe restablecerse. Así, por ejemplo, en la Sentencia del 28 de junio de 2012 se lee:

Ahora bien, en materia contractual, ha entendido la Sección Tercera que la entrada en vigencia de una ley tributaria puede llegar a afectar o a alterar el equilibrio del contrato, advirtiendo en todo caso que si el tributo es impuesto por la entidad estatal contratante se está frente al hecho del príncipe, pero si la contratante no es quien crea el gravamen se está en la teoría de la imprevisión.

\section{SÍ HAY LUGAR AL RESTABLECIMIENTO DEL EQUILIBRIO ECONÓMICO: LA VÍA ES LA TEORÍA DE LA IMPREVISIÓN}

Este escrito considera que el establecimiento de un tributo o la modificación de alguno o varios de sus elementos sí son eventos susceptibles de alterar el equilibrio económico de un contrato estatal. Siendo así, corresponde considerar a los argumentos que se oponen a tal reconocimiento y enfrentar sus reparos.

El primer argumento indica que el restablecimiento del equilibrio económico alterado por la imposición o modificación de un tributo apareja el traslado de la obligación fiscal a la entidad contratante y, finalmente, sería el propio Estado quien resulte gravándose a sí mismo. Este raciocinio contiene tres cuestiones distintas sobre las que vale detenerse. La primera, relativa a la circunstancia de que la entidad contratante cancele el valor del tributo y la posibilidad de que, por tal motivo, se altere el sujeto pasivo, se puede formular así: ¿si la entidad contratante asume el pago del gravamen, ello comporta el traslado de la obligación fiscal, de manera que se modificaría el sujeto pasivo de esta? Las otras dos atañen a la particularidad de que una entidad pública, la entidad contratante, resulte siendo deudora de otra, lo que tiene una implicación jurídica y otra práctica: ¿si la entidad contratante se hace cargo de la cancelación del valor del

"las sentencias judiciales están compuestas por tres partes: la parte resolutiva o decisum, que generalmente sólo obliga a las partes en litigio; la ratio decidendi que puede definirse como 'la formulación general, más allá de las particularidades irrelevantes del caso, del principio, regla o razón general que constituyen la base de la decisión judicial específica. Es, si se quiere, el fundamento normativo directo de la parte resolutiva'; y los obiter dicta o dictum que son 'toda aquella reflexión adelantada por el juez al motivar su fallo, pero que no es necesaria a la decisión, por lo cual son opiniones más o menos incidentales en la argumentación del funcionario"'. Corte Constitucional, Sentencia T-446 de 2013. 
tributo, operaría la confusión, como modo de extinción de las obligaciones, ya que el Estado sería deudor de sí mismo? y, finalmente, cpierde el tributo su propósito y utilidad, pues el dinero recaudado proviene del mismo patrimonio al que se dirigirá? El tributo es creado por un acto general y abstracto que define íntegramente sus elementos y estos solo pueden modificarse mediante otro acto de igual categoría, de manera que si algún elemento es alterado de otra forma habría un desconocimiento del acto que los creó y, por tanto, dicha variación sería contraria al ordenamiento.

En el ordenamiento colombiano, los actos generales y abstractos de los cuales nace la obligación fiscal son: la ley, en los tributos creados o cuya creación autoriza el Congreso; la ordenanza, si quien impone el gravamen es una asamblea departamental ${ }_{;}$y el acuerdo, tratándose de las cargas impositivas que le corresponde establecer a los concejos municipales y distritales, debiéndose en todos los casos definir los elementos del tributo o determinar la manera en que estos serán fijados ${ }^{15}$. Extraordinariamente, el Gobierno Nacional puede "establecer nuevos tributos o modificar los existentes" (art. 215 de la Constitución), lo que se trata de una facultad normativa especial otorgada al presidente en virtud de los estados de excepción y sujeta a las reglas que la Carta prevé para tales contingencias. Como quiera que la anterior facultad normativa se lleva a cabo mediante la expedición de decretos legislativos, tal imposición tributaria también tiene lugar a través de un acto general y abstracto. En conclusión, el tributo y sus elementos únicamente pueden establecerse y modificarse por las normas enunciadas.

Podría pensarse que como la entidad contratante asume el pago del tributo, a consecuencia del restablecimiento de la ecuación financiera, ocupando la entidad contratante el lugar que la obligación fiscal le da al contratista, habría un desconocimiento de la norma que establece el gravamen, pues el sujeto pa-

Artículo 338 de la Constitución: "En tiempo de paz, solamente el Congreso, las asambleas departamentales y los concejos distritales y municipales podrán imponer contribuciones fiscales o parafiscales. La ley, las ordenanzas y los acuerdos deben fijar, directamente, los sujetos activos y pasivos, los hechos y las bases gravables, y las tarifas de los impuestos". Sobre el principio de legalidad en materia tributaria la Corte Constitucional ha expresado: "(i) son los órganos de elección popular quienes directamente deben señalar los sujetos activo y pasivo, el hecho y la base gravable y la tarifa de las obligaciones tributarias, pues

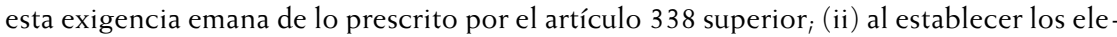
mentos del tributo, es menester que la ley, las ordenanzas o los acuerdos determinen con suficiente claridad y precisión todos y cada uno de los elementos esenciales del mismo; (iii) sólo cuando la falta de claridad sea insuperable, se origina la inconstitucionalidad de la norma que determina los elementos de la obligación tributaria (iv) el requisito de precisión y claridad -de- las normas que señalan los elementos de la obligación tributaria no se opone al carácter general de dichas normas ${ }_{i}(\mathrm{v})$ no se violan los principios de legalidad y certeza del tributo cuando uno de los elementos del mismo no está determinado expresamente en la norma, pero es determinable a partir de ella". Corte Constitucional, Sala Plena, Sentencia C-121 de 2006. 
sivo solo puede ser modificado a través de la expedición de otra norma de igual categoría. Sin embargo, este razonamiento se equivoca al confundir el título jurídico del que emana la obligación fiscal -el acto creador del tributo-, con aquel que fundamenta el deber de restaurar la ecuación financiera: el principio del equilibrio económico del contrato estatal. En efecto, el Estatuto General de Contratación de la Administración Pública dispone que en "los contratos estatales se mantendrá la igualdad o equivalencia entre derechos y obligaciones surgidos al momento de proponer o de contratar" (art. 27 de la Ley 80). Aquel cuerpo normativo también se encarga de desarrollar este principio mediante la imposición concreta de obligaciones, de esta forma prescribe que las entidades contratantes "actuarán de tal modo que por causas a ellas imputables, no sobrevenga una mayor onerosidad en el cumplimiento de las obligaciones a cargo del contratista" (art. 4.9 de La ley 80), deber que se acompaña del derecho correlativo de los contratistas "a que la administración les restablezca el equilibrio de la ecuación económica del contrato a un punto de no pérdida por la ocurrencia de situaciones imprevistas que no [les] sean imputables" (art. 5.1 de la Ley 80). La administración contratante está entonces en el deber de mantener y, cuando ello no sea posible, restaurar la ecuación financiera del contrato estatal ${ }^{16}$. Para tal efecto están la teoría de la imprevisión y los títulos de imputación: sujeciones materiales imprevistas, potestas variandi y hecho del príncipe, cuyo fundamento es el principio del equilibrio económico.

La diferencia entre el título jurídico del que nace la obligación fiscal y aquel en virtud del cual la administración contratante queda obligada a restablecer el equilibrio económico se hace ostensible si se observan las consecuencias jurídicas que están llamadas a producir. De un lado, el acto creador del tributo hace nacer la obligación de dar una suma de dinero, cuyo deudor, acreedor, causación y monto están definidos por él. De otro lado, los títulos de imputación -sujeciones materiales imprevistas, potestas variandi y hecho del príncipe-producen la obligación de resarcir los perjuicios que se hayan irrogado al contratista como resultado de su ocurrencia, pues son casos de responsabilidad contractual de la administración. Por su parte, la teoría de la imprevisión tiene el efecto de restaurar la ecuación financiera en su sentido más estricto, la reposición exacta del monto en que haya incurrido el contratista, sin lugar

16 "Por lo tanto, es propio del contrato del Estado el derecho de las partes al mantenimiento y restablecimiento del equilibrio financiero y económico de los contratos celebrados [...]". Jaime SANTOFimio, "El carácter conmutativo y por regla general sinalagmático del contrato estatal y sus efectos respecto de la previsibilidad del riesgo y del mantenimiento de su equilibrio económico", Revista digital de Derecho Administrativo, n. ${ }^{\circ}$ 1, primer semestre, Universidad Externado, 2009, p. 47. Disponible en línea: http://revistas.uexternado.edu. co/index.php/Deradm/article/view/2589/2228 [consultado el 4 de junio de 2017]. 
a ningún otro reconocimiento indemnizatorio o patrimonial ${ }^{17}$, por lo que en estos términos es una obligación compensatoria.

Para acabar de ver las diferencias entre las obligaciones que emanan bien del acto creador o modificador del tributo, o bien del principio del equilibrio económico, no está demás distinguir sus elementos estructurales: los sujetos y la prestación (contenido). Los sujetos de la obligación fiscal están determinados por el acto impositivo, mientras que los extremos subjetivos de la obligación resarcitoria o compensatoria, según sea el caso, son siempre las partes del contrato estatal. En cuanto al contenido, la materia de la cual versa la carga fiscal es la de dar una suma de dinero, determinada por los elementos base gravable y tarifa, mientras que la prestación de la obligación resarcitoria consiste en dejar indemne al contratista y la de la obligación compensatoria, en devolverle los valores en que haya incurrido.

El resto del argumento en consideración llama la atención sobre la particularidad de que la entidad contratante, siendo parte de la estructura estatal, termine como deudora del Estado. A primera vista parece un desatino que una entidad pública esté obligada al pago de una suma de dinero en favor de otra, pues al fin y al cabo son dineros públicos y están bajo la titularidad genérica del Estado. Tal apreciación merece más atención si se repara en que uno de los modos de extinción de las obligaciones es la confusión, que opera cuando en una persona concurren las calidades de deudor y acreedor ${ }^{18}, \mathrm{y}$, además, tratándose del restablecimiento de la ecuación financiera ocasionado por la imposición o modificación de tributos, el gravamen perdería eficacia, habida cuenta de que el dinero recaudado proviene del mismo lugar al que se dirigirá.

Aun siendo una república unitaria, Colombia está descentralizada administrativamente y sus entidades territoriales gozan de autonomía ${ }^{19}$ (art. 1 de la

"los efectos de la aplicación de la teoría de la imprevisión son compensatorios, limitados a un apoyo parcial y transitorio que se le da al contratista para solventar el quebranto o déficit que el hecho económico le origina en el cumplimiento de las obligaciones que emanan del contrato, sin que, por tanto, haya lugar al reconocimiento de beneficios diferentes a los mayores gastos, costos o pérdidas que resulten de soportar la circunstancia imprevisible, extraordinaria, grave y anormal y que haya podido sufrir el cocontratante, o sea, como señala la doctrina, de llevarlo a un punto de no pérdida y no de reparar integralmente los perjuicios". Consejo de Estado, Sección Tercera, Sentencia del 28 de junio de 2012, exp. 21.990

18 "Toda relación jurídica exige conceptualmente la presencia de dos sujetos, es decir, de dos personas diferentes $[\ldots]$ puede decirse que, cuando quiera que un una misma cabeza concurren las calidades de acreedor y deudor, de sujeto activo y de sujeto pasivo de la relación jurídica, esta se extingue por destrucción de su concepto, y que el ordenamiento lo que hace es reconocer dicha realidad ontológica". FERNANDO HinESTROSA, Tratado de las obligaciones I Concepto, estructura y vicisitudes, 3. ${ }^{\text {a }}$ ed., Bogotá: Universidad Externado, 2007, p. 767.

19 "La Constitución, en su artículo 1. ${ }^{\circ}$, estructura el Estado colombiano como una república unitaria, descentralizada y con autonomía de sus entidades territoriales [...]. Así, república unitaria implica que existe un solo legislador; descentralización consiste en la facultad que se otorga a entidades diferentes del Estado para gobernarse por sí mismas, a través de la 
Constitución). Las definiciones del modelo de Estado y la forma de gobierno previstas en la Carta conllevan a que los poderes públicos estén concentrados, con lo que hay un solo órgano legislativo, una única administración de justicia y un gobierno nacional, sin embargo el desarrollo de la actividad administrativa no corre esta suerte ${ }^{20}$. La descentralización administrativa posibilita el encargo de funciones administrativas a entidades públicas con personería jurídica propia, para que sean ejercidas con autonomía y bajo la entera responsabilidad de estas ${ }^{21}$.

Hay varios tipos de descentralización administrativa ${ }^{22}$ para el propósito de indagar por la pérdida de la eficacia del tributo, si su pago se hace con dineros públicos y de si una entidad pública puede resultar deudora de otra, vale considerar dos especies: la descentralización territorial y aquella que se hace por servicios. La propia Carta consagra el régimen jurídico de la primera ${ }^{23}$,

radicación de ciertas funciones en sus manos y autonomía significa la capacidad de gestión independiente de los asuntos propios. Etimológicamente, autonomía significa autonormarse, y de ella se derivan las siguientes consecuencias: a. Capacidad de dictar normas; $b$. Capacidad de la comunidad de designar sus órganos de gobierno; c. Poder de gestión de sus propios intereses y d. Suficiencia financiera para el desempeño de sus competencias". Corte Constitucional, Sentencia C-216 de 1994.

20 "Desde la Constitución de 1886, expedida en el período de la Regeneración, luego de haberse visto el fracaso de la forma de Estado Federal, Núñez y Caro buscaron reunificar el territorio nacional, mediante la fórmula centralización política y descentralización administrativa, con la cual se quiso significar, en suma, que las funciones constitucional, legislativa, judicial, de control y electoral, serían ejercidas desde solo un centro de impulsión, en tanto que la función ejecutiva o administrativa, sería descentralizada, territorialmente, por servicios y por colaboración. El constituyente de 1991, a más de conservar dichas directrices dentro del Título I, artículo $1 .{ }^{\circ}$, estableció el principio fundamental de la autonomía de las entidades territoriales, como mecanismo de acción. Así, con la descentralización se buscó una manera de administrar, dando mayor libertad en la toma de decisiones administrativas a las autoridades locales del orden territorial y funcional, en aras de lograr una mayor eficiencia y con la autonomía, grado creciente de libertad, se persiguió una mayor autodeterminación de los habitantes del territorio para el control de sus intereses y bienestar social". Consejo de Estado, Sección Segunda, Sentencia del 28 de enero de 1999, exp. 12.855.

21 "[La descentralización administrativa] Consiste en el otorgamiento de competencias o funciones administrativas a personas públicas diferentes del Estado, para que las ejerzan en su propio nombre y bajo su propia responsabilidad". LiBARDO RodríGuEZ, Derecho administrativo: General y colombiano, cit., p. 75.

22 "Ahora bien, existen varios tipos de descentralización, a saber: territorial, funcional o por servicios, por colaboración y, finalmente, por estatuto personal". Corte Constitucional, Sentencia C-1051 de 2001.

23 Además del artículo $1 .^{\circ}$, al que ya se hizo referencia, la Constitución prevé todo un título dedicado a regular la descentralización territorial. Se trata del Título XI que lleva por nombre "De la organización territorial" y contiene cuatro capítulos, en este orden: "De las disposiciones generales", "Del régimen departamental", "Del régimen municipal" y "Del régimen especial". 
además, también por mandato constituciona ${ }^{24}$, hay una ley orgánica de ordenamiento territorial encargada de establecer los parámetros a que el Congreso está sujeto en la expedición de leyes sobre la materia y en la actualidad es la número 1454. Precisamente esta ley establece a la descentralización como un principio, en virtud del cual "La distribución de competencias entre la Nación, entidades territoriales y demás esquemas asociativos se realizará trasladando el correspondiente poder de decisión de los órganos centrales del Estado hacia el nivel territorial pertinente" (art. 3 de la Ley 1454). La descentralización territorial hace de las entidades territoriales verdaderos centros de impulsión y desarrollo de la actividad administrativa, dotadas de personería jurídica de derecho público ${ }^{25}$ y con "autonomía para la gestión de sus intereses" (art. 287 de la Constitución). Gracias a ello, por ejemplo, los departamentos, los municipios y los distritos pueden celebrar contratos estatales, demandar judicialmente o ser llamados a juicio.

La descentralización por servicios o funcional trata de la distribución de la actividad administrativa en entidades públicas especializadas en determinados campos o labores ${ }^{26}$. La norma que regula este régimen jurídico es la Ley 489, que divide en dos escalas el reparto de funciones: el nivel central y el descentralizado por servicios (art. 38 de la Ley 489). Del primero hacen parte los organismos que conforman la administración nacional, tales como la Presidencia, los ministerios y los departamentos administrativos (arts. 38 y 39 de la Ley 489). Estos carecen de personería jurídica singular y, en consecuencia, sus actuaciones comprometen un centro de imputación jurídica común: la nación. Por el contrario, la nota característica de las entidades que conforman el sector descentralizado es su personería jurídica individual, complementada con autonomía administrativa y un patrimonio propio, tales como las empresas industriales y comerciales del Estado, y las sociedades de economía mixta.

24 Artículo 151 de la Constitución: "El Congreso expedirá leyes orgánicas a las cuales estará sujeto el ejercicio de la actividad legislativa. Por medio de ellas se establecerán los reglamentos del Congreso y de cada una de las Cámaras, las normas sobre preparación, aprobación y ejecución del presupuesto de rentas y ley de apropiaciones y del plan general de desarrollo, y las relativas a la asignación de competencias normativas a las entidades territoriales".

25 Artículo 80 de la Ley 153 de 1887: "La Nación, los Departamentos, los Municipios, los establecimientos de beneficencia y los de instrucción pública, y las corporaciones creadas ó reconocidas por la ley, son personas jurídicas"; artículo 4 del Código de Régimen Municipal: "La Nación, los Departamentos, las Intendencias, las Comisarías y los Municipios son personas jurídicas"; artículo 3 del Código de Régimen Departamental: "La Nación, los departamentos y los municipios son personas jurídicas".

26 "La descentralización funcional o por servicios consiste en la asignación de competencias o funciones del Estado a ciertas entidades, que se crean para ejercer una actividad especializada, tales como los establecimientos públicos, las corporaciones autónomas regionales, las empresas industriales y comerciales del Estado y las sociedades de economía mixta". Corte Constitucional, Sentencia C-1051 de 2001. 
Ya vislumbrado el anterior panorama del andamiaje estatal, no resulta extraño que dentro él hayan vínculos obligacionales entre las diversas entidades que lo conforman. Esto es posible por la descentralización territorial y por servicios, pues tanto las entidades territoriales como las entidades del sector descentralizado son personas jurídicas, dotadas de autonomía y un patrimonio propio, con lo que queda descartado que la confusión opere, ya que las calidades de deudor y acreedor no concurren en una misma persona. El ejemplo más notable de relaciones crediticias entre entidades del Estado lo constituyen los convenios de la administración, verdaderos negocios jurídicos por los que es posible que dos entidades públicas se obliguen recíprocamente ${ }^{27}$, permitiendo a la entidad acreedora conminar judicialmente a la entidad deudora para el cumplimiento de la prestación debida ${ }^{28}$.

Hay dos especies de convenios de la administración típicamente protagonizados por entidades públicas: los convenios interadministrativos y los contratos interadministrativos. Por los primeros se persigue un propósito afín entre las entidades que, entonces, entablan una relación de coordinación y cooperación ${ }^{29}$, sin que ello desnaturalice la noción de negocio jurídico, ya que las entidades, dotadas de personería jurídica y autonomía, modifican sus situaciones jurídicas externamente, es decir, se obligan por fuera de los vínculos establecidos entre ellas por el ordenamiento jurídico, creando sus propias relaciones jurídicas ${ }^{30}$. Mientras los segundos sí satisfacen los intereses particulares

27 "...] el convenio de la administración puede sintetizarse como [...] el negocio jurídico bilateral de la administración en virtud del cual ésta se vincula con otra persona jurídica pública o con una persona jurídica [...] natural [o] privada para alcanzar fines de interés mutuo en el marco de la ejecución de funciones administrativas, fines que, como es obvio, siempre deberán coincidir con el interés general". JorGE SANTOS, "Consideraciones sobre los contratos y convenios interadministrativos", Revista digital de Derecho Administrativo, n. ${ }^{\circ} 1$, primer semestre, Universidad Externado, 2009, p. 7. Disponible en línea: http://revistas.uexternado.edu.co/ index.php/Deradm/article/view/2592/2231 [consultado el 4 de junio de 2017].

28 "Las relaciones jurídicas surgidas del vínculo negocial generado por el convenio de la administración son de obligatorio cumplimiento por las partes involucradas, es decir, tienen plenos efectos jurídicos en el sentido de que las prestaciones deben ser ejecutadas, por lo cual se encuentran disponibles las herramientas legales y judiciales de coerción para lograr el efectivo cumplimiento de las prestaciones asumidas por cada una de las partes". Ibíd., pp. 7-8.

29 "[El] convenio interadministrativo [...] es el vínculo jurídico establecido mediante un acuerdo de voluntades celebrado entre dos o más personas jurídicas públicas con el objeto de coordinar, cooperar o colaborar en la realización de funciones administrativas de interés común a los sujetos contratantes". AuGUSTO CHÁvEZ, Los convenios de la administración: Entre la gestión pública y la actividad contractual, 2. ${ }^{a}$ ed., Bogotá: Universidad del Rosario, 2012, p. 112. "Atendiendo a los sujetos que los celebran debe indicarse que estos negocios jurídicos constituyen una de las manifestaciones de las relaciones interadministrativas, intersubjetivas o externas de la administración [...]. Por ello puede decirse que los convenios interadministrativos son vínculos de naturaleza contractual establecidos entre dos entidades que ostentan cada una de ellas personalidad jurídica, o entre órganos de dos personas jurídicas 
de los contratantes ${ }^{31}$, son contratos estatales en los que el contratista es una entidad territorial, una de las entidades del sector descentralizado por servicios o una de las entidades a las que la Constitución les concede un régimen especial, como las universidades públicas (art. 69 de la Constitución), las corporaciones autónomas regionales (art. 150.7 de la Constitución) o el Banco de la República (art. 371 de la Constitución). Por lo visto, no son extrañas ni mucho menos contrarias al ordenamiento las relaciones crediticias entre entidades del Estado. Tampoco el tributo pierde su eficacia de ser asumido por una entidad pública.

Si a consecuencia del restablecimiento económico el gravamen resulta siendo asumido con dineros públicos, no quiere decir que estos provengan de un solo patrimonio ni que estén afectados a las misas finalidades. Los valores recaudados de los tributos no están dirigidos a un fondo común, sino que, tomando en cuenta la distribución de la organización territorial, hay cargas fiscales destinadas exclusivamente para el nivel nacional, el departamental, el municipal y el distrital, esto explica que los gravámenes sean establecidos y modificados, respectivamente, mediante leyes, ordenanzas y acuerdos, como ya se había anotado. La contribución especial que adopta permanentemente la Ley $1738^{32}$ ilustra lo anterior, este gravamen dispone que, a la celebración o

públicas que actúan acudiendo a la condición de sujeto jurídico que se atribuye al ente del cual forman parte". Ibíd., p. 113.

31 "La celebración de un contrato interadministrativo enfrenta a dos partes: de un lado la administración que es titular de un servicio cuya satisfacción busca a través de la colaboración de otra persona jurídica pública, y de otro esta última, que al actuar como podría hacerlo un particular, se ubica en la condición de contratista al servicio de la persona jurídica pública contratante". Ibíd., p. 123.

32 La Ley 418 derogó expresamente a las leyes 104 y 241, que contenían al "impuesto de guerra", pero, en su lugar, creó una contribución especial que gravó el mismo supuesto de aquel: la celebración y la adición en el valor de los "contratos de obra pública para la construcción y mantenimiento de vías con entidades de derecho público" (artículo 120 original de la Ley 418). La vigencia de Ley 418 estuvo prevista para dos años, sin embargo fue ampliada por tres años más mediante la Ley 548. A su turno, la Ley 782 modificó la contribución especial, disponiendo que se causaría por la celebración o adición en el valor de contratos de obra pública para la construcción y mantenimiento de vías "de comunicación terrestre o fluvial, puertos aéreos, marítimos o fluviales" (artículo 37 original de la Ley 782). El término de vigencia de la Ley 782 fue de cuatro años. La Ley 1106 amplió por cuatro años más la contribución especial y la reformó nuevamente, estableciendo como hecho generador la celebración o la adición en el valor de contratos de obra pública, en general (artículo 6 de la Ley 1106). La contribución fue así prorrogada por la Ley 1421 para cuatro años más, hasta que, finalmente, la Ley 1738 la adopta permanentemente (parágrafo del artículo 8 de la Ley 1738). El vigente texto de la contribución especial es: "Todas las personas naturales o jurídicas que suscriban contratos de obra pública, con entidades de derecho público o celebren contratos de adición al valor de los existentes deberán pagar a favor de la Nación, Departamento o Municipio, según el nivel al cual pertenezca la entidad pública contratante una contribución equivalente al cinco por ciento $(5 \%)$ del valor total del correspondiente contrato o de la respectiva adición". 
adición de los contratos de obra pública, hecho generador, el contratista debe pagar el monto de la obligación fiscal "a favor de la Nación, Departamento o Municipio, según el nivel al cual pertenezca la entidad pública contratante".

Más aún, el Estado puede resultar gravado de forma directa, esto es, no a consecuencia del restablecimiento de la ecuación financiera, sino teniendo a una entidad pública como sujeto pasivo de la obligación fiscal. Nuevamente la contribución especial adoptada permanentemente por la Ley 1738 sirve de ilustración, el hecho generador del tributo en mención es la celebración o adición en el valor de contratos de obra pública, de manera que el contratista, sujeto pasivo del gravamen, bien puede ser una entidad estatal capaz de prestar la labor o servicios requeridos, por ejemplo, una universidad pública o una de las del sector descentralizado por servicios.

El segundo argumento que se opone al restablecimiento de la ecuación financiera alterada por el establecimiento de nuevos tributos o la modificación de los existentes, durante la ejecución de un contrato estatal, señala que la restitución no tiene lugar, habida cuenta de que en todo contrato se entienden "incorporadas las leyes vigentes al tiempo de su celebración", como lo ordena el artículo 38 de la Ley 153 de 1887 . Se precisa que la regla contenida en el artículo 38 de la Ley 153 de 1887 es propia de los negocios jurídicos entre particulares, sin embargo se aplica también a los contratos estatales, puesto que el Estatuto General de Contratación de la Administración Pública prevé que estos "se regirán por las disposiciones comerciales y civiles pertinentes" (art. 13 de la Ley 80). De esta manera, la censura es clara: las normas aplicables al contrato estatal son aquellas vigentes al tiempo de su perfeccionamiento y como uno de los supuestos del que pende la alteración del equilibrio económico es que se trate de una causa sobreviniente a este momento, la imposición o reforma de tributos en la fase de ejecución contractual no desbalancean la ecuación financiera, pues son eventos llevados a cabo mediante normas expedidas luego de la celebración del negocio jurídico. Con todo, este raciocinio se equivoca.

El error del anterior planteamiento consiste en pasar por alto la regla que determina específicamente los efectos de las normas tributarias en el tiempo. El último inciso del artículo 338 de la Constitución prevé: "Las leyes, ordenanzas o acuerdos que regulen contribuciones en las que la base sea el resultado de hechos ocurridos durante un período determinado, no pueden aplicarse sino a partir del período que comience después de iniciar la vigencia de la respectiva ley, ordenanza o acuerdo". De manera que utilizando los criterios generales de aplicación de la ley, ante normas susceptibles de regular el mismo supuesto de hecho, se concluye que prevalece la disposición consagrada en la Carta, pues lex superior derogat inferiori, además de que como esta se refiere concretamente a la vigencia de los tributos debe preferirse a la regla general del artículo 38 de la Ley 153 de 1887, ya que lex specialis derogat generali.

Queda por considerar el último argumento que se opone a reconocer la alteración del equilibrio económico, a causa de la imposición de obligaciones 
fiscales. El planteamiento en cuestión llama la atención sobre el hecho de que los tributos se establecen o reforman por actos generales y abstractos expedidos en el ejercicio legítimo de una competencia normativa, lo que hace que no haya lugar a restablecer las cargas económicas producidas por ellos, pues los sujetos pasivos tienen el deber jurídico de soportarlas y, además, todos quedan gravados en iguales términos. Como ya se había anotado, la importancia de esta réplica se halla en dejar sin efecto uno de los elementos necesarios para el surgimiento de la obligación de la administración a restaurar la ecuación financiera.

La Administración es responsable del restablecimiento de la ecuación financiera en tres eventos: por el descubrimiento o acaecimiento de obstáculos físicos que agravan la ejecución de las prestaciones a cargo del contratista, como, por ejemplo, los desperfectos geológicos o los fenómenos ambientales ${ }^{33}$; por el ejercicio de las prerrogativas derivadas de las cláusulas exorbitantes ${ }^{34} ;$ y por las alteraciones económicas producidas por el desarrollo de las funciones de la entidad contratante como autoridad pública ${ }^{35}$. Se trata de los títulos de imputación: sujeciones materiales imprevistas, potestas variandi y hecho del príncipe, en su orden. El acaecimiento de tales eventos no solo hace surgir para la Administración el deber de restablecer la ecuación financiera, sino que entraña responsabilidad. La jurisprudencia del Consejo de Estado ha manifestado que la administración contratante tiene la obligación de indemnizar los perjuicios irrogados al contratista, como consecuencia del suceso de sujeciones materiales imprevistas ${ }^{36}$, el

33 "[Las sujeciones materiales imprevistas] Son aquellas dificultades materiales que se presentan estrechamente relacionadas con la ejecución del contrato y que, aunque pudieran ser previsibles por la administración, aparecen de manera imprevista para el contratista, haciendo más difícil y gravosa dicha ejecución. Libardo RodríGuEZ, Derecho administrativo: general y colombiano, cit., p. 578.

34 "[La potestas variandi] Es una de las causales de ruptura del equilibrio económico consistente en que la administración pública contratante, al hacer uso legal de poderes conferidos por una cláusula exorbitante, altera anormalmente la economía del contrato, haciendo más gravosa su ejecución para una de las partes. La ocurrencia de una situación que dé lugar a la aplicación de esta causal genera como consecuencia el derecho a la indemnización integral a favor del contratista". Ibíd., pp. 578-579.

35 "[La teoría del hecho del príncipe] Se presenta cuando el equilibrio económico del contrato se rompe porque la entidad administrativa contratante, en ejercicio de atribuciones como autoridad pública y no como parte del contrato, expide actos jurídicos o cumple actuaciones materiales que lo afectan, haciendo considerablemente más oneroso para el contratista su fiel cumplimiento. La ocurrencia de una situación que dé lugar a la aplicación de esta teoría genera como consecuencia el derecho a la indemnización integral a favor del contratista". Ibíd., p. 577.

36 En lo que respecta las sujeciones materiales imprevistas "consisten en dificultades de tipo material o hechos de la naturaleza que ocurren en la ejecución del contrato y que las partes no pudieron prever al momento de celebrarlo, pero que inciden directamente en la cabal ejecución del mismo y, por tal motivo, en su economía, por cuanto implican, a la postre, mayores cantidades de obra o modificaciones técnicas tendientes a solucionarlas [...] en consecuencia, generan un daño antijurídico indemnizable a cargo de la entidad 
ejercicio de las potestas variandi ${ }^{37}$ y el desarrollo de actividades enmarcadas dentro de la teoría del hecho del príncipe ${ }^{38}$. Puesto que los títulos de imputación aludidos originan obligaciones indemnizatorias, no solo deben cumplir los requisitos concernientes a cada uno, sino que deben estar acompañados de los elementos estructurales de la responsabilidad: imputación, nexo causal y daño ${ }^{39}$. El argumento en consideración ataca precisamente al último de los elementos enunciados: el daño. La oposición a aceptar que el equilibrio económico del contrato estatal se altere por la creación o reforma de tributos se fundamenta en que las cargas económicas que estos producen no son daños susceptibles de indemnización, habida cuenta de que no son imposiciones antijurídicas y todos los sujetos pasivos quedan gravados en los mismos términos. De acuerdo con la regla general de responsabilidad del Estado, este responde "por los daños antijurídicos que le sean imputables" (art. 90 de la Constitución). El requisito para que el daño sea antijurídico ha sido entendido por la Corte Constitucional ${ }^{40}$ y el Consejo de

contratante, a título de responsabilidad objetiva o sin culpa". Consejo de Estado, Sección Tercera, Sentencia del 20 de noviembre de 2008, exp. 17.031.

37 Tratándose de las potestas variandi, "se configura cuando la administración en ejercicio de las potestades exorbitantes de interpretación, modificación y terminación unilaterales del contrato altera las condiciones existentes al momento de contratar", sin embargo "Este poder de modificación de la administración es limitado [... en todo contrato al disponerse la modificación de la realidad contractual, debe mantenerse el equilibrio económico del contrato, debiendo indemnizar al contratista cuando esas modificaciones produzcan la ruptura de ese equilibrio". Consejo de Estado, Sección Tercera, Sentencia del 31 de agosto de 2011, exp. 18.080.

38 Acerca del hecho del príncipe: "se presenta cuando la administración contratante [... profiere actos generales en su calidad de autoridad estatal, en ejercicio de sus propias funciones y no como parte contratante en el negocio jurídico, pero que tienen incidencia indirecta en el contrato y afectan su ecuación, generando una alteración extraordinaria o anormal de la misma, que ocasiona un detrimento de los intereses económicos del contratista, aunque a título de responsabilidad sin culpa". Consejo de Estado, Sección Tercera, Sentencia del 28 de junio de 2012, exp. 21.990.

39 "Aunque no hay uniformidad en la doctrina para determinar los elementos que se requieren para que exista responsabilidad, puede decirse que en el caso de la responsabilidad administrativa de ordinario se ha considerado que esos elementos son tres: una actuación de la administración, un daño o perjuicio y un nexo causal entre el daño y la actuación". Libardo RodríGuez, Derecho administrativo: General y colombiano, cit., p. 647.

40 "El daño antijurídico no tiene una definición constitucional expresa, por lo cual es un concepto constitucional parcialmente indeterminado, cuyos alcances pueden ser desarrollados, dentro de ciertos límites, por el Legislador. Sin embargo una interpretación sistemática de la Carta y de los antecedentes de la norma permiten determinar los elementos centrales de este concepto. [...] La doctrina española ha definido entonces el daño antijurídico no como aquel que es producto de una actividad ilícita del Estado sino como el perjuicio que es provocado a una persona que no tiene el deber jurídico de soportarlo. Esta concepción fue la base conceptual de la propuesta que llevó a la consagración del actual artículo 90. Así, la ponencia para segundo debate en la Plenaria de la Asamblea Constituyente señaló lo siguiente sobre este tema: '[...] La noción de daño en este caso, parte de la base de que el Estado es el guardián de los derechos y garantías sociales y que debe, por lo tanto, 
Estado $^{41}$ como la ausencia del deber jurídico de la víctima en soportarlo ${ }^{42}$, es decir, la falta de un título jurídico que permita la causación del perjuicio, específicamente, la inexistencia de una norma que justifique el detrimento patrimonial. De esta forma, si bien los tributos infligen una "aminoración patrimonial ${ }^{43 "}$ ", esta no es antijurídica, pues está amparada por las normas que crean y modifican los gravámenes. Incluso puede pensarse que, pese a la existencia un título jurídico que justifica la irrogación del perjuicio económico, haya un desbordamiento del normal reparto y asunción de las cargas públicas, daño especial, pero ello tampoco es admisible, ya que las normas tributarias son actos generales y abstractos que gravan a todos los sujetos pasivos en las mismas condiciones. Sin dudas, el argumento en consideración cuenta con razón al afirmar que las cargas económicas causadas por los gravámenes fiscales no son daños antijurídicos, con lo que deja sin fundamento la obligación indemnizatoria de la administración a restablecer los agravios patrimoniales que los tributos pudieran producir en las prestaciones debidas por los contratistas, sujetos pasivos. Sin embargo, los títulos de imputación que comprometen la responsabilidad de la administración contratante no son los únicos caminos para restituir el equilibrio económico, queda la teoría de la imprevisión. Las dificultades económicas que los tributos puedan causar en la ejecución de las prestaciones a cargo del contratista del Estado no son daños indemnizables, razón por la que queda descartada la búsqueda del restablecimiento económico a través de los títulos de imputación por los que la administración compromete su responsabilidad contractual. Pero estos no son la única vía para restaurar la ecuación financiera, los agravios patrimoniales irro-

reparar la lesión que sufre la víctima de un daño causado por su gestión, porque ella no se encuentra en el deber jurídico de soportarlo'". Corte Constitucional, Sentencia C-333 de 1996.

41 "Por lo anterior, conviene precisar que, de conformidad con el artículo 90 de la Constitución Política, esta Corporación ha sostenido que aunque el ordenamiento jurídico no contiene una disposición que consagre una definición de daño antijurídico, este se refiere a 'la lesión de un interés legítimo, patrimonial o extrapatrimonial, que la víctima no está en la obligación de soportar, que no está justificado por la ley o el derecho', de ahí que para que proceda declarar la responsabilidad del Estado con base en un título jurídico subjetivo u objetivo de imputación, se ha de probar la existencia de (i) el daño, el cual debe ser cierto y determinado o determinable, (ii) la conducta u omisión que generó el daño, atribuible a una autoridad pública y (iii) 'cuando hubiere lugar a ella, una relación o nexo de causalidad [entre los dos primeros elementos], vale decir, que el daño se produzca como consecuencia directa de la acción o la omisión atribuible a la entidad accionada"'. Consejo de Estado, Sección Tercera, Sentencia del 24 de octubre de 2016, exp. 34.357.

42 "Pero actualmente, dentro del contexto del artículo 90 de la Constitución colombiana [...] se requiere como elemento fundamental que el daño sea antijurídico en el sentido [...] de que el sujeto que lo sufre no tenga el deber jurídico de soportarlo". Libardo RodrícueZ, Derecho Administrativo: general y colombiano, cit., p. 649.

43 Juan Carlos Henao, El daño: Análisis comparativo de la responsabilidad extracontractual del Estado en derecho colombiano y francés, Bogotá: Universidad Externado, 1998, p. 84. 
gados por la imposición o reforma de gravámenes fiscales pueden compensarse mediante la teoría de la imprevisión.

Una vez finalizado el examen de los argumentos contrarios a admitir que el establecimiento de cargas tributarias dé lugar a la alteración de la ecuación financiera y, a su vez, hechas las anotaciones pertinentes, corresponde centrar la atención en la argumentación en favor de la restitución del equilibrio económico. La naturaleza del contrato estatal es ser un negocio jurídico bilateral, oneroso y conmutativo ${ }^{44}$, lo que significa que tanto la entidad contratante como el contratista asumen obligaciones recíprocamente, buscando la satisfacción de intereses singulares, motivo por el que cada uno acepta ejecutar en favor del otro prestaciones que miran como equivalentes al beneficio que esperan obtener. Reflejo de esta la naturaleza sinalagmática y conmutativa del contrato estatal es el principio del equilibrio económico ${ }^{45}$. Los extremos subjetivos de la relación contractual diseñan el contenido obligacional, tomando en cuenta los fines que pretenden lograr, y sellan su arreglo con la expectativa fundada de recibir el servicio, provecho o utilidad pactados. Sin embargo, cuando los efectos del negocio jurídico se dilatan en el tiempo, bien sea por la índole del acuerdo o por la inclusión de una modalidad accidental, el acontecimiento de circunstancias ajenas a los contratantes puede agravar la ejecución de las prestaciones o hacer que se pierda el valor del beneficio que se esperaba recibir. Para estas eventua-

44 "Entendemos entonces por contrato del Estado o estatal todo negocio jurídico, de contenido económico, consecuentemente oneroso, celebrado, por regla general, bajo los presupuestos del principio de igualdad, en aras del interés público o general, en el cual una de las partes es una entidad estatal, un particular que cumple funciones administrativas en los términos de la ley o cualquier otra persona que involucre en el mismo recursos públicos, y en razón del cual se generan, de manera discrecional, ponderada, proporcional y previsiva, obligaciones por regla general recíprocas, de dar, hacer o no hacer alguna cosa entre las partes intervinientes, construyendo, regulando o extinguiendo entre ellas relaciones jurídicas patrimoniales individuales no generales, debidamente planificadas, obligaciones que se miran como equivalentes conforme a las previsiones objetivas iniciales acordadas por las partes al momento de proponer o de contratar". JaImE SANTOFIMIO, "El carácter conmutativo y por regla general sinalagmático del contrato estatal y sus efectos respecto de la previsibilidad del riesgo y del mantenimiento de su equilibrio económico", cit., pp. 13-14.

45 "el principio general que surge y se manifiesta ostensible en el concepto de negocio del Estado propuesto en este trabajo es el del mantenimiento de su estructura original, derivada de las actuaciones y procedimientos previos, que signados por el concepto de discrecionalidad y con sujeción a los principios de ponderación, proporcionalidad y previsibilidad determinaron unas condiciones sobre las cuales se sustentó la propuesta y el contrato finalmente celebrado y que constituyen las condiciones estructurales sobre las cuales se debe ejecutar el contrato; estas condiciones están llamadas a permanecer durante la ejecución e incluso durante su liquidación, manteniéndose en estas instancias necesariamente las obligaciones y derechos originales y así también las contingencias y los riesgos previsibles que asumieron, aspectos que de llegar a surgir fenómenos que rompan el equilibrio que garantiza el legislador, deben de inmediato restablecerse". Ibíd., p. 47. 
lidades está el principio del equilibrio económico. El contenido del que versa este principio es el mantenimiento de la simetría contractual primigenia ${ }^{46}$. A las partes escapa el control de las contingencias naturales y el de los vaivenes sociales y económicos capaces de alterar la correspondencia entre las prestaciones debidas por cada una. De este efecto se ocupa el equilibrio económico que, sin desconocer el riesgo connatural que apareja toda relación negocial, morigera las afectaciones graves y extraordinarias de la ecuación financiera, tomando como referencia el acuerdo plasmado al momento del perfeccionamiento del contrato ${ }^{47}$, pues es el arreglo que los extremos subjetivos estimaron justo y proporcionado.

Habida cuenta de que el equilibrio económico es un principio, su aplicación es la regla general. Su contenido permea todas las relaciones contractuales de la administración que tengan carácter sinalagmático y conmutativo, a la vez que dirige el devenir de estas, en caso de que por causas anormales al desarrollo natural del contrato se agrave la ejecución de las prestaciones o se disminuya significativamente el beneficio esperado. Dado que la aplicación del principio del equilibrio económico es la regla general, sus excepciones deben estar expresamente consagradas $\mathrm{o}$, cuando menos, demostrarse argumentativamente que se trata de un supuesto ajeno a su ámbito regulatorio. Sin embargo, ninguna de las dos condiciones anteriores se presenta en el caso de las alteraciones económicas que puedan tener lugar, como consecuencia de la creación o reforma de tributos, en la ejecución del contrato estatal. Ninguna norma exceptúa a las imposiciones tributarias de la aplicación del principio del equilibrio económico. Tampoco hay suficiente fundamento en los argumentos que se oponen a reconocer que los agravios producidos por los gravámenes fiscales sean eventos de alteración de la ecuación financiera. Si, de un lado, se acepta que los detrimentos patrimoniales originados por la creación o reforma de tributos no son daños antijurídicos, con lo que se descarta su restablecimiento mediante los títulos de imputación que comprometen la responsabilidad contractual de la administración, por otro lado, queda despejado el camino, a través de la teoría de la imprevisión, como líneas atrás se expuso.

46 "El principio del equilibrio financiero del contrato, medular en el régimen jurídico de la contratación pública, consiste, entonces, en garantizar el mantenimiento de la igualdad o equivalencia entre derechos y obligaciones surgidos al momento de proponer o de contratar, según el caso". Consejo de Estado, Sección Tercera, Sentencia del 28 de junio de 2012, exp. 21.990.

47 "En virtud del principio de la ecuación financiera o equilibrio económico del contrato se persigue que la correlación existente al tiempo de su celebración entre las prestaciones que están a cargo de cada una de las partes del contrato, permanezca durante toda su vigencia, de tal manera que a la terminación de este, cada una de ellas alcance la finalidad esperada con el contrato". Consejo de Estado, Sección Tercera, Sentencia del 28 de junio de 2012, exp. 21.990 . 
Otro argumento que juega a favor del restablecimiento de las alteraciones económicas causadas por los tributos es la jurisprudencia del Consejo de Estado. Esta Corporación ha admitido que la ecuación financiera de los contratos estatales puede resultar alterada con motivo de la imposición o reforma de gravámenes fiscales, indicando como posibles fundamentos a la teoría de la imprevisión y al hecho del príncipe. Aunque vale advertir que se trata de pasajes conceptuales, sin verdadera incidencia en las decisiones finales, obiter dicta. Tan solo en una ocasión el Máximo Tribunal Contencioso Administrativo aplicó la teoría del hecho del príncipe. En sentencia del 27 de marzo de 1992, el Consejo de Estado analizó la alteración del equilibrio económico de un contrato estatal para el "diseño, fabricación y entrega de cables monopolares de cobre". Durante la ejecución de este negocio jurídico cobraron vigencia nuevos tributos que hicieron notablemente cuantiosa la obligación a cargo del contratista, consistente en la importación de la materia prima necesaria para la producción del cableado. El contrato estatal aludido contenía una cláusula por la cual el contratista debía pagar "todos los impuestos y derechos que con base o por razón de este contrato, llegue a cobrar el gobierno colombiano". De otro lado, el pliego de condiciones con que se llevó a cabo el procedimiento de selección encargaba al contratista el pago de "los impuestos, derechos y gastos de legalización del contrato que por motivo de él cobre el gobierno colombiano". Se aprecia que un texto y el otro difieren en relación con las cargas asumidas por el contratista, el primero le atribuía el riesgo de las imposiciones tributarias futuras, mientras que el segundo solo le hacía asumir los gravámenes fiscales vigentes al momento de la celebración del contrato ${ }^{48}$. El Consejo de Estado resolvió esta contrariedad dando prevalencia a lo dispuesto originalmente por el pliego de condiciones ${ }^{49}$, ya que fue en consideración de él que el contratista realizó la propuesta. Tras superar la anterior situación problemática, el Máximo Tribunal Contencioso Administrativo se metió de lleno en la cuestión relativa a la alteración del equilibrio económico causada por la entrada en vigencia de nuevos tributos, que hicieron más onerosa la ejecución de la obligación del contratista, en relación con las cargas econó-

"Mientras el pliego señala que los impuestos, derechos y gastos de legalización que por motivo de él cobre el gobierno colombiano los pagará el contratista, la cláusula contractual introduce una nota de futuro ('llegue a cobrar el gobierno') que como tal obliga al contratista no sólo a pagar los vigentes al momento de su legalización sino todos aquellos que se establecieron en el futuro. La diferencia de forma y contenido es fundamental, ya que el pliego habrá que entenderlo con referencia a los derechos, impuestos y gastos exigibles al momento de su legalización y no en relación con otras obligaciones futuras que no existían a la sazón". Consejo de Estado, Sección Tercera, Sentencia del 27 de marzo de 1992, exp. 6353.

49 "la cláusula contractual (impuestos y derechos) modificó ilegalmente el pliego de condiciones en dicho extremo y no obliga a la contratista". Consejo de Estado, Sección Tercera, Sentencia del 27 de marzo de 1992, exp. 6353. 
micas inicialmente previstas, al momento de la celebración del contrato. De esta forma, aquella Corporación precisó:

Es bien sabido que el equilibrio financiero de un contrato administrativo puede sufrir alteración por un hecho imputable al Estado, como sería, entre otros, el conocido doctrinariamente como hecho del príncipe y determinante del área administrativa. Hecho, siempre de carácter general, que puede emanar o de la misma autoridad contratante o de cualquier órgano del Estado.

Bajo esta concepción de la teoría del hecho del príncipe, el Consejo de Estado encontró que sí hubo una alteración de la ecuación financiera en el contrato puesto bajo su consideración. Se resalta la circunstancia de que en esta oportunidad el Máximo Tribunal Contencioso Administrativo desarrolló y aplicó la vertiente "amplia" o "lata" de la teoría del hecho del príncipe, consistente en considerar dentro de su ámbito regulatorio los actos generales dictados por autoridades públicas distintas de la entidad contratante. El antecedente jurisprudencial que se comenta fue el primero y, hasta ahora, el único en aplicar la teoría del hecho del príncipe a una situación problemática de desequilibrio económico ocasionada por gravámenes fiscales. Antes, en sentencia del 11 de febrero de 1983, el Consejo de Estado hizo mención del hecho del príncipe y de la teoría de la imprevisión como los posibles fundamentos teóricos para el restablecimiento de las alteraciones patrimoniales resultantes de la imposición de tributos, pero su referencia no dejó de ser más que enunciativa, pues la Litis se decidió bajo otras justificaciones jurídicas. Más recientemente están las providencias en que el Máximo Tribunal Contencioso Administrativo se ocupó de examinar a los contratos de obra pública que gravó el "impuesto de guerra", pero las circunstancias propias de cada caso no cumplieron con los requisitos necesarios para la restitución de la ecuación financiera.

El "impuesto de guerra", como se le conoció comúnmente ${ }^{50}$, fue una contribución especial creada por el Decreto Legislativo 2009 de 1992, prorrogada por el Decreto Legislativo 1515 de 1993 y adoptada por la Ley 104 ${ }^{[51]}$. Durante

50 'La contribución especial, comúnmente denominada 'impuesto de guerra', fue creada por el Gobierno Nacional al amparo del estado de conmoción interior, por el Decreto Legislativo 2009 de 14 de diciembre de 1992, con el fin de dotar a las fuerzas armadas de fuentes de financiación". Consejo de Estado, Sección Tercera, Sentencia del 28 de junio de 2012, exp. 21.990.

51 La disposición del Decreto Legislativo 2009 de 1992 que contemplaba el "impuesto de guerra" señalaba: "Art. 1. ${ }^{\circ}$. Todas las personas naturales o jurídicas que, a partir de la vigencia del presente Decreto, suscriban contrato de obra pública para la construcción y mantenimiento de vías con entidades de derecho público, o celebren contratos de adición al valor de los existentes, deberán pagar a favor de los entes territoriales respectivos, de acuerdo con el nivel al cual pertenezca la entidad pública contratante, una contribución equivalente al $5 \%$ del valor total del correspondiente contrato o de la respectiva adición". Fue así prorrogado por el Decreto Legislativo 1515 de 1993 y, más adelante, adoptado 
su vigencia, este tributo gravó la celebración y la adición en el valor de los contratos de obra pública cuyo objeto fuera la "construcción y mantenimiento de vías", y ya que la adición evidentemente tiene lugar en la fase de ejecución contractual, fue una oportunidad propicia para que el Máximo Tribunal Contencioso Administrativo estudiara la posibilidad de que dicha contribución alterara el equilibrio económico. En sentencia del 29 de mayo del 2003, primera providencia en indagar si las adiciones gravadas por el "impuesto de guerra" ocasionaban desequilibrio económico, el Máximo Tribunal Contencioso Administrativo emprendió sus consideraciones señalando que la ecuación financiera del contrato estatal es susceptible de alterarse, además de por el ejercicio de poderes exorbitantes, por "actos de la administración como Estado" y "por factores externos y extraños a las partes" e indicó:

El primer tipo de actos se presenta cuando la administración actúa como Estado y no como contratante. Allí se encuentra el acto de carácter general proferido por este, en la modalidad de ley o acto administrativo (hecho del príncipe); por ejemplo, la creación de un nuevo tributo, o la imposición de un arancel, tasa o contribución que afecten la ejecución del contrato. Y en los factores externos, se encuentran las circunstancias de hecho que de manera imprevista surgen durante la ejecución del contrato, ajenas y no imputables a las partes, que son manejadas con fundamento en la teoría de la imprevisión.

En el primero de los apartes reproducidos se observa que el Consejo de Estado continuó teniendo a las imposiciones tributarias como casos de hecho del príncipe, pero decidió cambiar un aspecto de esta teoría, en relación con lo que había precisado en la sentencia del 27 de marzo de 1992. Así, en la sentencia del 29 de mayo del 2003 se lee:

La Sala considera que sólo resulta aplicable la teoría del hecho del príncipe cuando la norma general que tiene incidencia en el contrato es proferida por la entidad contratante. Cuando la misma proviene de otra autoridad se estaría frente a un evento externo a las partes que encuadraría mejor en la teoría de la imprevisión.

La decisión del Máximo Tribunal Contencioso Administrativo en restringir el ámbito de aplicación del hecho del príncipe se debió a la falta de imputación

por el artículo 123 de Ley 104, que mantuvo casi idéntica la disposición primigenia con la siguiente redacción: "Todas las personas naturales o jurídicas que suscriban contratos de obra pública para la construcción y mantenimiento de vías con entidades de derecho público o celebren contratos de adición al valor de los existentes, deberán pagar a favor de la Nación, departamentos o municipios, según el nivel al cual pertenezca la entidad pública contratante, una contribución equivalente al cinco por ciento $(5 \%)$ del valor total del correspondiente contrato o de la respectiva adición". 
del agravio económico a la entidad contratante ${ }^{52}$. Las dificultades patrimoniales suscitadas por un acto normativo general expedido por una autoridad distinta a la entidad contratante no son atribuibles a esta, pues son circunstancias que escapan a su esfera de control. Con todo, ante este impedimento, el Consejo de Estado acepta que la restitución de la ecuación financiera alterada por el establecimiento o reforma de disposiciones de carácter general, como las tributarias, se puede encuadrar en la teoría de la imprevisión. A pesar de que, dentro de las consideraciones de la providencia en cuestión, el Consejo de Estado precisó al detalle los supuestos y requisitos de la teoría del hecho del príncipe y de la teoría de la imprevisión, aceptando que las dos podían justificar el restablecimiento económico de los agravios suscitados por gravámenes fiscales, la decisión final fue tomada sin emplear a ninguna de ellas. El caso se despachó desfavorablemente a la parte que solicitó la restitución de la ecuación financiera, pues no probó que las adiciones gravadas por el "impuesto de guerra" hayan aumentado extraordinariamente sus $\operatorname{costos}^{53}$, además, comoquiera que el contratista contó con una partida contractual específicamente destinada a sufragar los imprevistos, debió acreditar que las cargas ocasionadas por el "impuesto de guerra" superaban lo dispuesto en dicha cláusula, pero tampoco ocurrió asi ${ }^{54}$.

Las anteriores consideraciones acerca de la alteración del equilibrio económico causada por imposiciones tributarias fueron reproducidas en las subsiguientes providencias que se encargaron de estudiar también las adiciones gravadas por el "impuesto de guerra": Sentencia del 19 de febrero de 2009, exp. 19.055; Sentencia del 4 de febrero de 2010, exp. 15.400; Sentencia del 4 de febrero de

52 "En relación con la condición de la autoridad que profiere la norma general, para la doctrina y la jurisprudencia francesa el becho del príncipe (le fait du prince) se configura cuando la resolución o disposición lesiva del derecho del cocontratante emana de la misma autoridad pública que celebró el contrato, lo cual permite afirmar que constituye un caso de responsabilidad contractual de la administración sin culpa. La justificación de esta posición radica en la ausencia de imputación del hecho generador del perjuicio cuando este proviene de la ley, por cuanto el autor del acto (Nación, Congreso de la República) puede ser distinto de la administración contratante. No obstante no se priva al contratista de la indemnización ya que podrá obtenerla a través de la aplicación de la teoría de la imprevisión". Consejo de Estado, Sección Tercera, Sentencia del 29 de mayo de 2003, exp. 14.577.

53 "Concluye la Sala de lo anterior, que si lo que pretendía la sociedad demandante era demostrar que con la retención del $5 \%$ sobre algunas de las cuentas del contrato se afectaron las utilidades previstas al momento de su celebración, en forma grave, tal circunstancia no se acreditó suficientemente.". Consejo de Estado, Sección Tercera, Sentencia del 29 de mayo de 2003, exp. 14.577

54 "En el presente caso, no se pretende afirmar que con dicha partida el contratista pudo cubrir el nuevo impuesto que afectó los pagos que se le hicieron por concepto del valor de los contratos adicionales, sino que correspondía a este demostrar que la partida de gastos de imprevistos resultó insuficiente para cubrir el perjuicio económico o disminución de la utilidad que dijo haber sufrido por el pago de la contribución". Consejo de Estado, Sección Tercera, Sentencia del 29 de mayo de 2003, exp. 14.577. 
2010, exp. 15.665; Sentencia del 4 de febrero de 2010 exp. 16.017; Sentencia del 18 de enero de 2012, exp. 19.304 y Sentencia del 28 de junio de 2012, exp. 21.990. En dichas oportunidades se aceptó que el restablecimiento de la ecuación financiera podía llevarse a cabo mediante la teoría de la imprevisión o la teoría del hecho del príncipe, sin embargo no fueron aplicadas y en ninguno de tales casos se reconoció que haya habido una ruptura del equilibrio económico.

Para culminar con los comentarios a la jurisprudencia del Consejo de Estado sobre la alteración del equilibrio económico por imposiciones tributarias, vale destacar dos cuestiones. No obstante que ninguna de las vías admitidas para restablecer la ecuación financiera en estos casos, teoría de la imprevisión y hecho del príncipe, han sido aplicadas a la solución concreta de los casos, con excepción de la Sentencia del 27 de marzo de 1992, hay un reconocimiento que deja la puerta abierta para las futuras situaciones problemáticas de rompimiento de la ecuación financiera a causa de gravámenes fiscales. Finalmente, se hace expresa una diferencia: no se coparte con la jurisprudencia del Máximo Tribunal Contencioso Administrativo que la restitución del equilibrio económico pueda llevarse a cabo mediante el hecho del príncipe, pues este título entraña responsabilidad y los perjuicios patrimoniales irrogados por la creación o reforma de tributos no son daños antijurídicos, por lo que tampoco son indemnizables, asunto que ya tuvo la oportunidad de exponerse.

\section{LOS REQUISITOS DE LA TEORÍA DE LA IMPREVISIÓN Y LOS INSTRUMENTOS QUE PRECAVEN SU OCURRENCIA}

Como se vio, la teoría de la imprevisión es el mecanismo por el que se debe restablecer el equilibrio económico desbalanceado por la imposición o modificación de un tributo. Sin embargo, no todos los agravios patrimoniales producidos por los gravámenes fiscales tienen la dimensión de alterar la ecuación financiera. Para determinar en qué casos sí y en qué otros no hay lugar a aplicar la teoría de la imprevisión, lo primero es indagar por sus requisitos. En sentencia del 29 de mayo del 2003, el Máximo Tribunal Contencioso Administrativo precisó que la teoría de la imprevisión se "presenta cuando situaciones extraordinarias, ajenas a las partes, imprevisibles y posteriores a la celebración del contrato alteran la ecuación financiera del mismo en forma anormal y grave, sin imposibilitar su ejecución". Con observancia de la anterior definición, que también es acorde con lo que expresa la doctrina ${ }^{55}$, se puede concluir

55 "La teoría de la imprevisión tiene cabida cuando situaciones extraordinarias, ajenas a la voluntad de las partes, que sean de naturaleza imprevisibles y que se presenten con posterioridad a la celebración del contrato, alteran la ecuación financiera del mismo en forma anormal y grave, sin imposibilitar su ejecución". ERnESTO MatalLANA, Manual de contratación de la administración pública: Reforma de la Ley 80 de 1993, 3. ${ }^{a}$ ed., Bogotá: Universidad Externado, 2013, pp. 356-357. 
que la creación o reforma de gravámenes fiscales puede romper la ecuación financiera de los contratos estatales siempre que: se trate de una imposición o modificación sobrevenida a la celebración del contrato, es decir, durante la fase de ejecución, sea un hecho imprevisto o imprevisible para las partes ${ }_{i}$ también debe ser una contingencia exógena a ellas, no atribuible al contratista ni a la entidad contratante ${ }_{i}$ tiene que tener carácter extraordinario, lo que denota su falta de pertenencia al alea normal del tipo contractual en cuestión; $y_{\text {, por }}$ último, debe generar una alteración trascendental del equilibrio contractual, capaz de agravar considerablemente el cumplimiento de las obligaciones, pero no la suficiente para constituir una imposibilidad absoluta ${ }^{56}$.

La mayoría de los requisitos son claros y no merecen mayor explicación. De una parte, es necesario que la alteración patrimonial se produzca después de celebrado el negocio jurídico, pues si se trata de un desequilibrio congénito, vertido en el contenido del acuerdo, los instrumentos procedentes para su restablecimiento serían otros (lesión enorme, precio irrisorio, cláusula abusiva), también es diáfano que el desbalance financiero debe provenir de un factor externo a las partes, una circunstancia que no pueda ser imputable a ellas, de otro modo se estaría ante un evento de responsabilidad contractual, donde entraría en juego la valoración de la diligencia de quien debía ejecutar la obligación ${ }^{57}$. Asimismo, es preciso que se trate de un agravio económico con suficiente fuerza para producir un desequilibrio en las prestaciones pactadas originalmente, pero no tanta para que haga de estas una encomienda de imposible cumplimiento, como sería el acaecimiento una fuerza mayor o caso fortuito ${ }^{58}$, entrando a operar la teoría de los riesgos. De otro lado, hay requisitos que merecen ser apreciados con más detalle. Se trata de la imprevisibilidad y la anormalidad de la circunstancia que origina el desequilibrio. La primera consiste en que ninguna de las partes puede estimar razonable y anticipadamente las peripecias que terminan haciendo excesivamente oneroso

56 Sobre los requisitos de la teoría de la imprevisión en los contratos estatales: Consejo de Estado, Sección Tercera, Sentencia del 28 de junio de 2012, exp. 21.990.

57 "Es elemental la consideración de que los hechos modificativos de las circunstancias imperantes a la época en que se pactaron los deberes no pueden derivar de actividad del propio deudor $\mathrm{y}$, mucho menos, de una negligencia, un descuido, una temeridad de su parte. A semejanza de lo que ocurre con la imposibilidad sobrevenida, hipótesis en la que incumbe al obligado probar no solamente la razón específica de su no cumplimiento, sino además que el obstáculo se presentó sin su culpa (art. $1604\left[20^{\circ}\right]$ c.c. $)^{\prime \prime}$. FernandO Hinestrosa, Tratado de las obligaciones II. De las fuentes de las obligaciones: El negocio jurídico, vol. 2, Bogotá: Universidad Externado, 2015, p. 521.

58 "[La teoría de la imprevisión] [s]e diferencia del caso fortuito porque el contrato puede cumplirse, pero el costo que tendría sería tan alto que principios de equidad permiten a la parte obligada solicitar su revisión ante un juez". JORGE DuSSÁn, El equilibrio económico en los contratos administrativos, Bogotá: Universidad Jorge Tadeo Lozano, 2005, p. 226. 
el cumplimiento de las prestaciones a cargo de la parte afectada. La segunda condición va de la mano del tipo o especie contractual en cuestión. Cada negocio jurídico envuelve una operación económica singular, caracterizada por un desarrollo propio y a la que le pertenecen ciertos riesgos, un álea normal.

No cabe duda de que el establecimiento o la modificación de tributos son circunstancias imprevisibles. Al tratarse del ejercicio de una competencia normativa, principalmente desarrollada mediante la expedición de leyes, la creación o reforma de tributos depende en buena medida de vaivenes económicos, sociales y políticos. Un ejemplo servirá para ilustrar las continuas variaciones en materia tributaria. Como ya se había mencionado, el "impuesto de guerra" se creó con el Decreto Legislativo 2009 de 1992, fue prorrogado por el Decreto Legislativo 1515 de 1993 y, luego, lo adoptó la Ley 104 por el término de dos años. Al cabo de este periodo, la Ley 241 prorrogó por dos años más la contribución, hasta que la Ley 418 derogó expresamente a las leyes 104 y 241 (artículo 131 de la Ley 418) y con ellas el "impuesto de guerra", sin embargo, en su lugar, estableció otra contribución que gravó el mismo supuesto de aquel: la celebración y la adición en el valor de los "contratos de obra pública para la construcción y mantenimiento de vías con entidades de derecho público" (artículo 120 original de la Ley 418). La vigencia de Ley 418 estuvo prevista para dos años, sin embargo fue ampliada por tres años más mediante la Ley 548 . A su turno, la Ley 782 modificó la contribución especial, disponiendo que se causaría por la celebración o adición en el valor de contratos de obra pública para la construcción y mantenimiento de vías "de comunicación terrestre o fluvial, puertos aéreos, marítimos o fluviales" (artículo 37 original de la Ley 782). El término de vigencia de la Ley 782 fue de cuatro años. La Ley 1106 amplió por cuatro años más la contribución especial y la reformó nuevamente, estableciendo como hecho generador la celebración o la adición en el valor de contratos de obra pública, en general (artículo 6 de la Ley 1106). La contribución fue así prorrogada por la Ley 1421 para cuatro años más, hasta que, finalmente, la Ley 1738 la adoptó permanente e indefinidamente (parágrafo del artículo 8 de la Ley 1738). Se aprecia con claridad que no es razonablemente posible anticipar los cambios en materia tributaria. Bien se puede estar en presencia de un tributo al que su norma de creación le prevé un término de vigencia determinado, pero al cabo del cual es prorrogado por otro periodo igual o mayor, o también pudo haber tenido reformas en alguno o varios elementos durante el tiempo de su vigor, $y$, en fin, se pueden dar una serie de variables que son propias del albur social, económico y político que rodea la actividad legislativa.

En lo que respecta al requisito de la anormalidad, también tomando en cuenta que la imposición o reforma de tributos implica el desarrollo de una competencia normativa, es, por lo mismo, ajena a las circunstancias propias que rodean la actividad económica del objeto del contrato en cuestión. Bien se ve que para que las imposiciones tributarias sean eventos de desequilibrio económico deben pasar un juicio bastante estricto, a lo que se aúna una serie de 
mecanismos contractuales y legislativos cuyo propósito es prever y evitar que sobrevengan circunstancias capaces de alterar la ecuación financiera. Tres de estos instrumentos preventivos buscan particularmente evitar que los agravios patrimoniales acaecidos con posterioridad al perfeccionamiento del contrato tengan la entidad de alterar el equilibrio económico. Se trata de la distribución de riesgos, las partidas económicas destinadas a sufragar imprevistos y las disposiciones especiales contenidas en los actos que crean o modifican el tributo.

\subsection{LA DISTRIBUCIÓN DE RIESGOS}

El artículo 4 de Ley 1150 ordena que los pliegos de condiciones "deberán incluir la estimación, tipificación y asignación de los riesgos previsibles involucrados en la contratación". Se trata de un desarrollo del principio de planeación ${ }^{59}$. En virtud de este, las entidades que se dispongan a desplegar su actividad contractual deben primero realizar las investigaciones pertinentes al objeto del contrato que pretendan celebrar, principalmente a través de la elaboración de estudios previos y, posteriormente, con la expedición del pliego de condiciones, que condensa toda la información en forma de reglas que disciplinan tanto el procedimiento de selección como el contrato a celebrar.

Con fundamento en los estudios previos y demás indagaciones preliminares, la entidad vislumbra las peripecias que pueden suceder durante la ejecución del contrato que pretende celebrar. De esta manera, por mandato de la norma citada, así como en ejercicio de su autonomía de la voluntad (arts. 32 y 40 de la Ley 80), la entidad distribuye el riesgo de las contingencias contractuales, asignando a quién corresponde soportar los agravios que estos puedan ocasionar. De estas previsiones no escapan el establecimiento de tributos y su modificación. El riesgo tributario, precisamente aquel que sucede cuando en la ejecución del contrato se crean tributos o se reforman los vigentes, es generalmente dejado en cabeza del contratista ${ }^{60}$, a través de una estipulación contractual al respecto. Sin embargo, la existencia de una cláusula en este sentido no está exenta de reparos. Como ya tuvo la oportunidad de anotarse, el establecimiento o la modificación de tributos son circunstancias imprevisibles y los riesgos de esta naturaleza no pueden asignarse contractualmente en cabeza del contratista. Si

59 "La jurisprudencia de la Sala ha sostenido repetidamente, y así lo reitera ahora, que en materia contractual, las entidades oficiales están obligadas a respetar y a cumplir el principio de planeación en virtud del cual resulta indispensable la elaboración previa de estudios y análisis suficientemente serios y completos, antes de iniciar un procedimiento de selección". Consejo de Estado, Sección Tercera, sentencia del 29 de agosto de 2007, exp. 14.854.

$60 \mathrm{Al}$ respecto puede consultarse el esquema comparativo de las cláusulas de distribución de riesgos en algunos contratos estatales que realiza Ernesto Matallana. Cfr. ERNESTO MatALLANA, Manual de contratación de la administración pública: Reforma de la Ley 80 de 1993, cit., pp. 364-389. 
bien la administración, en desarrollo de su actividad contractual, tiene el deber de distribuir los riesgos, el propio artículo 4 de Ley 1150 señala expresamente que los que son objeto de asignación son los "previsibles involucrados en la contratación", de manera que los demás, razonablemente imprevisibles por las partes al momento del perfeccionamiento del negocio jurídico, constituyen el supuesto de hecho de aplicación del principio del equilibrio económico y, en concreto, de la teoría de la imprevisión.

También se anota que la inclusión de una cláusula contractual que ponga en cabeza del contratista un riesgo imprevisible trastoca la naturaleza conmutativa que caracteriza el contrato estatal, para convertirlo en uno de índole aleatoria ${ }^{61}$. Esto no es todo, una estipulación en tal sentido implicaría la renuncia general y anticipada del derecho del contratista al restablecimiento del equilibrio económico y como este principio, así como el conjunto de normas que forman el Estatuto General de Contratación de la Administración Pública, es de orden público ${ }^{62}$, habría un desbordamiento de la autonomía de la voluntad de los extremos subjetivos de la relación contractual estatal ${ }^{63}$. El propio Estatuto General de Contratación de la Administración Pública sanciona con ineficacia de pleno derecho a las disposiciones de los pliegos que incluyan "condiciones

61 "Sin embargo, y en ello se debe tener especial cuidado, es necesario que con el traslado de riesgos al contratista, no se esté desvirtuando la naturaleza eminentemente conmutativa de los contratos estatales [...], pues no es posible legalmente convertir este contrato en un contrato aleatorio; por consiguiente, es preciso concluir que no es posible trasladar al contratista aquellos riesgos no cuantificables o que no sean mesurables o definibles (riesgo por cambio legislativo fiscal, ambiental. imprevisión etc.), pues por ese sólo hecho se convertiría la naturaleza del contrato en aleatorio (la incertidumbre de la ganancia o pérdida es la característica esencial de este tipo de contratos artículo 1498 Código Civil)". Susana MOnTES y PATRICIA Mier, "Concesiones viales. La inadecuada distribución de los riesgos, eventual causa de crisis en los contratos", Revista de Derecho Público, n. ${ }^{\circ} 11$, primer semestre, Universidad de los Andes, 2000, pp. 67-68. Disponible en línea: https://derechopublico. uniandes.edu.co/index.php?option $=$ com_revista\&view $=$ inicio\&idr $=27 \% 3 \mathrm{ARevista} \_11 \& \mathrm{I}$ temid $=111$ \&lang $=$ es [consultado el 4 de junio de 2017].

62 "De este modo, el equilibrio financiero constituye un eje fundamental de la contratación administrativa y, gracias a la expedición de la Ley 80 de 1993, la obligación de su mantenimiento es una norma de imperativo cumplimiento para las partes". MANUELA CANAL, "La aplicación del equilibrio económico a contratos estatales sometidos al régimen normativo de derecho privado", Revista digital de Derecho Administrativo, n. ${ }^{\circ} 15$, primer semestre, Universidad Externado, 2016, p. 148. Disponible en línea: http://revistas.uexternado.edu.co/ index.php/Deradm/article/view/4591/5279 [consultado el 4 de junio de 2017].

63 "En efecto, en la medida en que se reconoce que las normas que regulan el principio de equilibrio económico son de orden público y envuelven mínimos de protección que no son renunciables en abstracto o de manera general, habrá de concluirse que un modelo de distribución de riesgos que pretenda hacer una mecánica asignación de los mismos al contratista debe ser ineficaz". FeRNANDO SILVA, "Una aproximación a la visión de la corrección del desequilibrio contractual desde la perspectiva de la jurisprudencia arbitral", Revista e-Mercatoria, vol. 6, n. ${ }^{\circ}$ 2, Universidad Externado, 2007, p. 21. Disponible en línea: http://revistas.uexternado.edu. co/index.php/emerca/article/view/2062 [consultado el 4 de junio de 2017]. 
y exigencias de imposible cumplimiento" (art. 24.5. numeral d de la Ley 80), aquellas que contengan "exenciones de la responsabilidad derivada de los datos, informes y documentos que se suministren" (art. 24.5. numeral d de la Ley 80) y las que impliquen "ofrecimientos de extensión ilimitada o que dependan de la voluntad exclusiva de la entidad" (art. 24.5. numeral e de la Ley 80), previsiones normativas que comprenden las renuncias generales y anticipadas del derecho del contratista al restablecimiento del equilibrio económico.

\subsection{LAS PARTIDAS ECONÓMICAS DESTINADAS A SUFRAGAR IMPREVISTOS}

En algunos contratos estatales suele incluirse una partida económica destinada a compensarle al contratista los riesgos que puedan realizarse en la fase de ejecución. El más conocido es el denominado factor "Alu"64, cuyas siglas significan: administración, imprevistos y utilidades. Se trata de una estipulación accidental que discrimina los costos del contratista, como forma de asegurarle una retribución justa, que no tenga que verse mermada con el suceso de eventos adversos que escapen a su esfera de control. Aunque no hay un régimen jurídico respecto de este tipo de cláusulas contractuales ${ }^{65}$, lo cierto es que su objeto es reconocer anticipadamente los agravios patrimoniales que puedan surgir en el desarrollo del contrato estatal. De esta forma, cuando el contratista pretenda el restablecimiento de la ecuación financiera alterada por la imposición de gravámenes tributarios, deberá acreditar que la partida de imprevistos no es suficiente para efectuar el pago de la obligación fiscal, es decir que, aun contando con los recursos afectados a sufragar este tipo de contingencias, la ejecución de las prestaciones a cargo de la parte gravada con el tributo sigue siendo excesivamente onerosa.

\subsection{LAS DISPOSICIONES ESPECIALES CONTENIDAS EN LOS ACTOS QUE CREAN O MODIFICAN EL TRIBUTO}

Finalmente, están todas aquellas previsiones normativas contenidas en el acto que crea o reforma el tributo y que en forma expresa establecen los efectos de

64 "El Alu es el factor de remuneración del contratista calculado sobre el valor total del contrato, el cual comprende los gastos en que se incurre por la ejecución del contrato (administración), un porcentaje para los riesgos que puedan presentarse (imprevistos) y la justa utilidad a que tiene derecho el contratista por la ejecución de la labor encomendada". JORGE DuSSÁn, El equilibrio económico en los contratos administrativos, cit., p. 225.

65 "En nuestro régimen de contratación estatal, nada se tiene previsto sobre la partida para gastos imprevistos y la jurisprudencia se ha limitado a reconocer el porcentaje que se conoce como AlU -administración, imprevistos y utilidades-como factor en el que se incluye ese valor, sobre todo, cuando el juez del contrato debe calcular la utilidad del contratista, a efecto de indemnizar los perjuicios reclamados por este". Consejo de Estado, Sección Tercera, Sentencia del 29 de mayo de 2003, exp. 14.577. 
este en el tiempo, tomando en cuenta los contratos estatales que gravan. La reforma tributaria, Ley 1819, consagra un ejemplo muy ilustrativo. Dicha ley, mediante su artículo 184, que, a su vez, modificó el artículo 468 del Estatuto Tributario, aumentó en 3 puntos porcentuales la tarifa del impuesto sobre las ventas $^{66}$. La propia Ley 1819, tomando en cuenta las implicaciones que podía tener sobre la ecuación financiera de los contratos estatales en ejecución, dispuso lo siguiente:

Artículo $192^{\circ}$. Contratos celebrados con entidades públicas. La tarifa del impuesto sobre las ventas aplicable a los contratos celebrados con entidades públicas o estatales, será la vigente en la fecha de la resolución o acto de adjudicación, o suscripción del respectivo contrato. Si tales contratos son adicionados, a dicha adición le son aplicables las disposiciones vigentes al momento de la celebración de dicha adición.

\section{CONCLUSIONES}

Tanto el establecimiento de nuevos tributos como su reforma durante la ejecución del contrato estatal son eventos capaces de alterar el equilibrio económico de este. Se descarta sin embargo que el restablecimiento del equilibrio económico alterado por la creación o reforma de tributos pueda encausarse por los títulos de imputación: sujeciones materiales imprevistas, potestas variandi y, especialmente, hecho del príncipe. De esta manera, la vía para restituir el equilibrio económico alterado por la imposición de gravámenes fiscales es la teoría de la imprevisión. Para que la restitución por conducto de la teoría de la imprevisión se abra paso, es necesario que el tributo se cree o reforme con posterioridad al perfeccionamiento del contrato y que cause que la ejecución de las prestaciones a cargo de la parte gravada sea excesivamente onerosa. En cuanto a los demás requisitos que debe presentar la contingencia generadora del desequilibrio -ausencia de imputación a la parte afectada, imprevisibilidad y anormalidad-, quedan acreditados por las condiciones en que los tributos se crean y reforman, mediante la expedición de normas y en observancia de unas peripecias económicas, sociales y políticas determinadas. No obstante, es necesario tener en cuenta las partidas destinadas a sufragar imprevistos y los actos de creación o reforma del tributo. Respecto de las primeras se debe acreditar su insuficiencia. Por el lado de las normas que imponen o modifican obligaciones fiscales, es necesario que no haya un pronunciamiento expreso en relación con los efectos en el tiempo que el tributo esté llamado a producir sobre de los contratos estatales que grava.

66 Artículo 184 de la Ley 1819: "Modifíquese el artículo 468 del Estatuto Tributario el cual quedará así: ARTí́CULO 468. TARIFA GENERAL DEL IMPUESTO SOBRE LAS VENTAS. La tarifa general del impuesto sobre las ventas es del diecinueve por ciento (19\%) salvo las excepciones contempladas en este título". 


\section{BIBLIOGRAFÍA}

\section{DOCTRINA}

BENAVIDES, LuIs, El contrato estatal: Entre el derecho público y el derecho privado, Bogotá: Universidad Externado, 2 ed., 2004.

Canal, Manuela, "La aplicación del equilibrio económico a contratos estatales sometidos al régimen normativo de derecho privado", Revista digital de Derecho Administrativo, n. ${ }^{\circ}$ 15, primer semestre, Universidad Externado, 2016.

Chávez, Augusto, Los convenios de la administración: Entre la gestión pública y la actividad

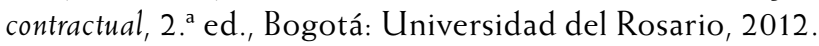

DuSSÁN, JORGE, El equilibrio económico en los contratos administrativos, Bogotá: Universidad Jorge Tadeo Lozano, 2005.

Henao, Juan Carlos, El daño: Análisis comparativo de la responsabilidad extracontractual del Estado en derecho colombiano y francés, Bogotá: Universidad Externado, 1998.

Hinestrosa, Fernando, Tratado de las obligaciones I: Concepto, estructura y vicisitudes, Bogotá: Universidad Externado, 3 ed., 2007.

Hinestrosa, Fernando, Tratado de las obligaciones it. De las fuentes de las obligaciones: El negocio jurídico, vol. 2, Bogotá: Universidad Externado, 2015.

INSIGNARES, ROBERTO Y SÁNCHEZ, MARY, "El poder tributario: organización y estructura en el Estado colombiano", en Julio Piza (ed.), Curso de derecho tributario, procedimiento y régimen sancionatorio. Bogotá: Universidad Externado, 2010.

Matallana, ERnesto, Manual de contratación de la administración pública: Reforma de la Ley 80 de 1993, 3. ${ }^{a}$ ed., Bogotá: Universidad Externado, 2013.

Montes, Susana y Mier, Patricia, "Concesiones viales. La inadecuada distribución de los riesgos, eventual causa de crisis en los contratos", Revista de Derecho Público, n. ${ }^{\circ} 11$, primer semestre, Universidad de los Andes, 2000.

RodríGUEZ, LiBARDo, El equilibrio económico en los contratos administrativos, 2. a ed., Bogotá: Temis, 2012.

RodríGUEZ, Libardo, Derecho administrativo: General y colombiano, 19. ed., Bogotá: Temis, 2015.

SAnTOFimio, JAIME, "El carácter conmutativo y por regla general sinalagmático del contrato estatal y sus efectos respecto de la previsibilidad del riesgo y del mantenimiento de su equilibrio económico", Revista digital de Derecho Administrativo, n. ${ }^{\circ}$ 1, primer semestre, Universidad Externado, 2009

SAnTOS, JoRGE, "Consideraciones sobre los contratos y convenios interadministrativos", Revista digital de Derecho Administrativo, n. ${ }^{\circ}$, primer semestre, Universidad Externado, 2009. 
Silva, Fernando, "Una aproximación a la visión de la corrección del desequilibrio contractual desde la perspectiva de la jurisprudencia arbitral", Revista e-Mercatoria, vol. 6, n² 2, Universidad Externado, 2007.

JURISPRUDENCIA

\section{Jurisprudencia de la Corte Constitucional}

Corte Constitucional, Sentencia C-216 de 1994.

Corte Constitucional, Sentencia C-583 de 1996.

Corte Constitucional, Sentencia C-333 de 1996.

Corte Constitucional, Sentencia C-1051 de 2001.

Corte Constitucional, Sentencia C-121 de 2006.

Corte Constitucional, Sentencia T-446 de 2013.

\section{Jurisprudencia del Consejo de Estado}

Consejo de Estado, Sección Tercera, Sentencia del 27 de marzo de 1992, exp. 6353.

Consejo de Estado, Sección Segunda, Sentencia del 28 de enero de 1999, exp. 12.855.

Consejo de Estado, Sección Tercera, Sentencia del 29 de mayo de 2003, exp. 14.577.

Consejo de Estado, Sección Tercera, Sentencia del 2 de septiembre de 2004, exp. 14.578 .

Consejo de Estado, Sección Tercera, Sentencia del 29 de agosto de 2007, exp. 14.854.

Consejo de Estado, Sección Tercera, Sentencia del 20 de noviembre de 2008, exp. 17.031 .

Consejo de Estado, Sección Tercera, Sentencia del 19 de febrero de 2009, exp. 19.055.

Consejo de Estado, Sección Tercera, Sentencia del 4 de febrero de 2010, exp. 15.400.

Consejo de Estado, Sección Tercera, Sentencia del 4 de febrero de 2010, exp. 15.665.

Consejo de Estado, Sección Tercera, Sentencia del 4 de febrero de 2010, exp. 16.017.

Consejo de Estado, Sección Tercera, Sentencia del 31 de agosto de 2011, exp. 18.080.

Consejo de Estado, Sección Tercera, Sentencia del 28 de junio de 2012, exp. 21.990.

Consejo de Estado, Sección Tercera, Sentencia del 18 de enero de 2012, exp. 19.304.

Consejo de Estado, Sección Tercera, Sentencia del 24 de octubre de 2016, exp.: 34.357. 